\section{Limbic lesions and cue utilization in the} Dashiell maze 1, 3

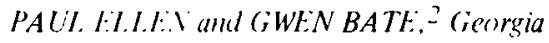
State L'nirersitr', Atlanta, Ga. 30303

Septally lesioned, hippocampally lesioned, and unoperated rats were trained for 20 dars in one of two conditions in a Dashiell maze. In one maze condition, the peripheral paths were black and the center paths were white, while in the other, the reverse was the case. When the center paths were black and peripheral paths white, lesioned animals, as well as control, preferred center pathways. Although all animals preferred the black peripheral routes in the white-center naze condition. septal animals made significantly fewer errorless nuns in this condition. This latter observation reflected an enhanced aversiveness by the septal animals for the white pathwal's.

In a previous study, we reported (Ellen $\&$ Bate, 1969) that rats with septal lesions preferred the outside, L-shaped rather than the inside zigzag pathways in a Dashiell maze. Inasmuch as the maze in the original study was all black and did not contain any apparent differential external cues, we hypothesized that the septal animal's preference for the outer or peripheral pathways resulted from the loss or failure to utilize response-produced stimuli as discriminative cues for the alternation of turns in running the inside zigzag pathways.

The question arose, however, as to the extent to which exteroceptive cues, if incorporated in the maze, would cause septal animals to choose the inside zigzag pathways. This possibility was further suggested by the findings of Ellen \& Butter (1969), who showed that the overresponding by septal animals on a DRL schedule could be attenuated by the use of an external cue light to signal the end of the required delay.

Thus, the present study is concerned with determining if rats with limbic lesions will choose zigzag pathways in the maze when such pathways are differentially cued.

\section{PROCEDURE}

Twenty-nine male Long-Evans hooded rats, approximately 100 days old, ranging in weight from 225 to $300 \mathrm{~g}$ at the start of the experiment, were used.

The apparatus was a checkerboard maze originally described by Dashiell (1930). Modifications of his basic design included higher posts and walls (11 in.) and 10-in.-long goal- and startboxes separated from the maze by guillotine doors. In addition, two inserts, one painted flat black and one painted flat white, were constructed so that the maze could be assembled in either one of two arrangements, namely, a black center with white peripheral pathways or a white center with black peripheral pathways. In either case, the start-and goalboxes were the same brightness (black or white) as the inner pathway (Fig. 1).

The maze was placed on a table in the center of an experimental cubicle, in which there was a fluorescent ceiling light over the maze.

Preoperatively, the animals were housed two to four to a cage, with ad lib food and water. Each animal was handled $2-5 \mathrm{~min}$ a day for 1 week. Subsequently, the animals were divided randomly into three groups: 9 septal, 10 hippocampal, and 10 unoperated controls. All surgery was performed under $\mathrm{Nembutal}$ anesthesia, $40 \mathrm{mg} / \mathrm{kg}$, supplemented by atropine sulfate $(0.16 \mathrm{mg})$ to prevent respiratory complications. Stereotaxically oriented electrolytic lesions ( $2 \mathrm{~mA}$ for $15 \mathrm{sec}$ ) were produced between the anodal electrode in the brain and a probe at the wound margin. The stereotaxic coordinates were as follows: In the case of septal lesions, the electrode was located $1.5 \mathrm{~mm}$ anterior to bregma on the midline suture and lowered to a depth $5.5 \mathrm{~mm}$ below the surface of the brain. For the hippocampal lesions, the electrode was positioned $3.5 \mathrm{~mm}$ anterior to the interaural line and $3 \mathrm{~mm}$ laterally to the longitudinal suture. The electrode was lowered $3.5 \mathrm{~mm}$ below the surface of the brain.

Postoperatively, the animals received $.20 \mathrm{cc}$ Duracillin (procaine penicillin) and were housed in separate cages with ad lib food and water.

On the sixth postoperative day, the animals were placed on a 23-h food-deprivation schedule, and training to run in a straight alley for wet mash was initiated. This procedure was continued for 6 days. Subsequently, training in either one of the two arrangements of the Dashiell maze was begun.

Half of the animals in each group were assigned to either the Dashiell maze consisting of the white center with black peripheral paths, and vice versa. Each animal was run one trial per day for 20 days in his respective maze, with $30 \mathrm{~g}$ of wet mash as a reward. At the end of each trial, the animals were returned to their home cages and allowed to finish their daily ration.

Following maze training, the animals were sacrificed with a lethal dose of Nembutal and perfused intracardially with isotonic saline followed by $10 \%$ formalin. Frozen sections, 50 microns thick, were photographed as wet slides to determine lesion location and extent. Figure 2 illustrates the typical extent and locus for each of the lesion groups.

\section{RESULTS}

Table 1 ( $A$ and $B$ ) shows the acquisition of the goal orientation habit for various groups. Two measures of acquisition were taken: errors and errorless paths. An error was counted whenever an animal entered a blind alley or turned in a direction away from the goal. An errorless path was a run to the goal in which no errors occurred. Whether a run contained a single error or multiple errors, it did not meet the criterion of an errorless path. A 2 by 3 factorial analysis of variance (unweighted means analysis, Winer, 1962) showed that, with respect to the average number of errors made by the various groups, no significant effects were found either for mazes $(F=1.43, p>.05)$, lesion conditions $(F=2.54, p>.05)$ or Maze by Lesion interaction $(F=2.97, p>.05)$.
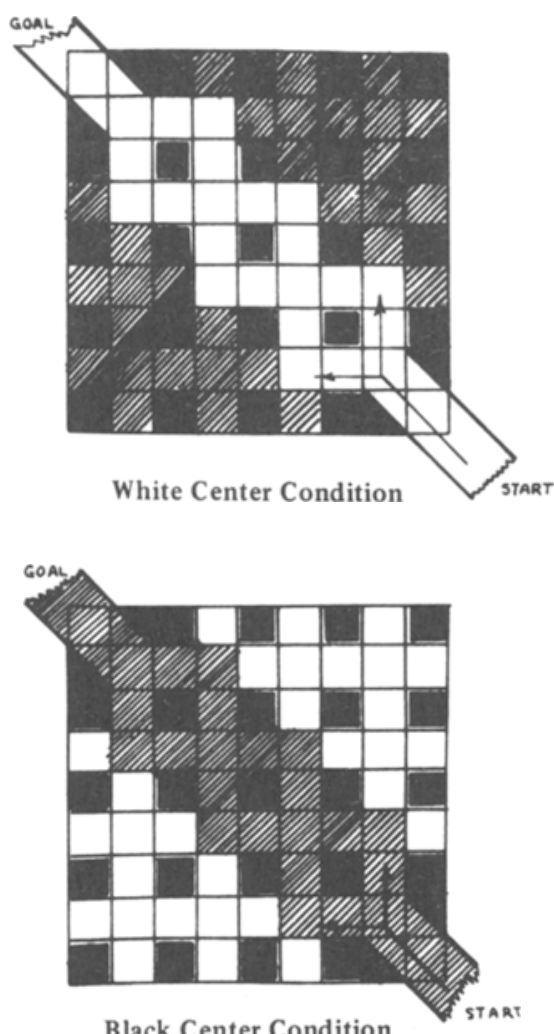

Fig. 1. Dashiell maze showing arrangement of black and white inserts. The black squares indicate location of posts and are black for illustrative purposes only. 


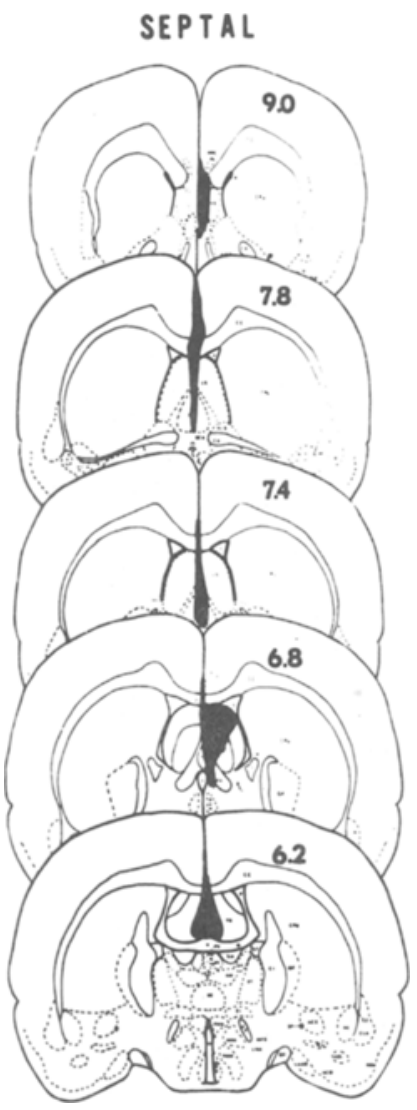

However, an analysis of the frequency with which the various groups ran errorless trials showed a significant Maze by Lesion interaction $(F=4.81, p<.01)$. Septal animals made significantly fewer errorless runs in the white-center maze condition.

Table 1(C) shows the variability of the animals' preference in each of the maze conditions. It will be recalled that in a Dashiell maze an animal can choose any one of 20 different routes of equal distance to the goal on each trial. A 2 by 3 analysis of variance on the arc-sin transformed percentages revealed no significant effects, either with respect to mazes $(F=1.33$, $p>05)$, lesions $(F=0.67, p>05)$ or interaction $(F=0.0)$.

Although there was no difference in the variability of preferences for the various groups in each of the mazes, both lesion and mazes influenced the preference for the kind of pathway chosen. That is, when the black-center maze was used, over $90 \%$ of the errorless paths run by all groups were of the inside zigzag variety. However, when the white-center maze condition was used, the preference by all groups for the inside pathway markedly declined. This difference in preference as a function of maze condition was significant $(F=103.5$, $p<.01)$. In addition, lesioned animals chose the inside pathway significantly less

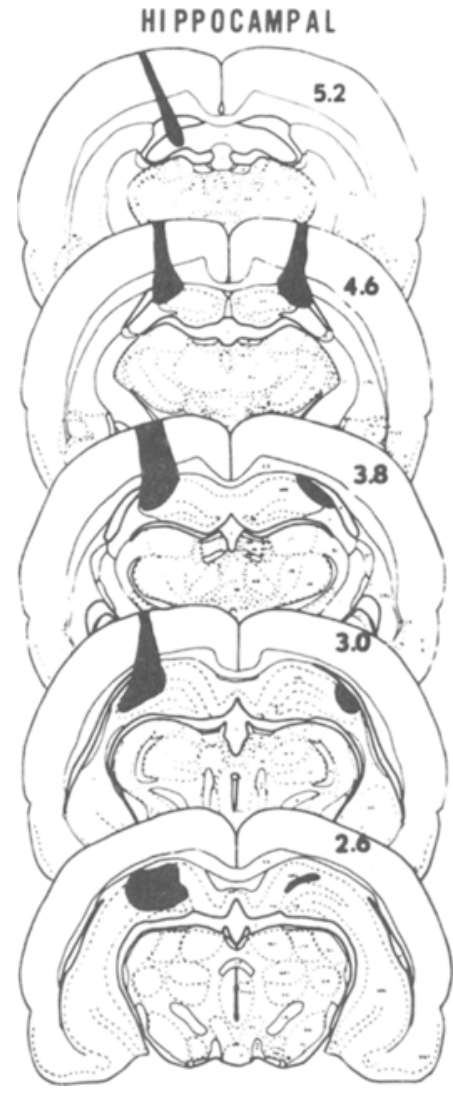

frequently than did normal animals $(F=4.61, \quad p<.05)$. No significant interaction between maze condition and lesions was found on this measure of preference $(F=2.69, p>.05)$. These results are shown in Table I(D). DISCUSSION

It would appear, then, that the kind of path, inside zigzag or peripheral L-shaped, chosen by the lesioned animals depends on the kind of exteroceptive cues present in the maze. Thus, lesioned animals as well as normal animals were able to take inside zigzag paths in the maze provided the inside pathways were black and the peripheral pathways white. When the opposite occurred, lesioned animals took fewer inside paths than did the controls. This observation lends support to the hypothesis proposed by Ellen \& Bate (1969) that the preference of septally lesioned animals for the peripheral L-shaped pathways in an all-black Dashiell maze having no apparent differential exteroceptive cues was the result of a failure of response-produced stimulation to provide discriminative cues for the alternation of turns. Whether this resulted from a loss of sensory input or a failure or inability to utilize the response-produced stimulation cannot be determined at present.
Fig. 2. Representative septal and hippocampal lesions as reconstructed on frontal diagrammatic plates from the Pellegrino \& Cushman atlas (1967). Each section is identified with the appropriate A.P. stereotaxic coordinates.

Of particular interest was the unexpected finding of the apparently greater aversiveness of the white pathways for the septal as compared to the hippocampal and control animals. Even though the preference for center pathways was reduced for all groups when the pathway was white, septal animals made significantly fewer errorless runs in this condition. That is, even though the septal animals were running their preferred route (i.e., a peripheral pathway), they still made fewer errorless runs. This finding most likely can be accounted for by the observation that when the septal animals were ready to leave the black peripheral pathway and turn into the white path directly in front of the goal, as the arrangement of the maze required (see Fig. 1), they exhibited numerous turns away from the goal as well as crouching and stretching behaviors, all of which suggest an enhanced aversion to the white pathway. Of interest in this connection is the report by Schwartzbaum et al (1967) of a heightened aversive reaction to visual stimulation shown by septal animals in an avoidance task. In that study, septals showed an enhanced tendency to escape light when light-on was a CS and a significantly reduced shuttling behavior between illuminated and darkened compartments in a shuttlebox. Moreover, this enhanced reactivity persisted after other manifestations of hyperreactivity disappeared.

The basis for such an enhanced aversion to light is not evident from behavioral data. of particular interest in this connection, however, are the findings of Lorens \& Brown (1967) who showed that septal stimulation attenuated cortical potentials evoked by light. This would lead to the

Table 1

Indices of Maze Performance

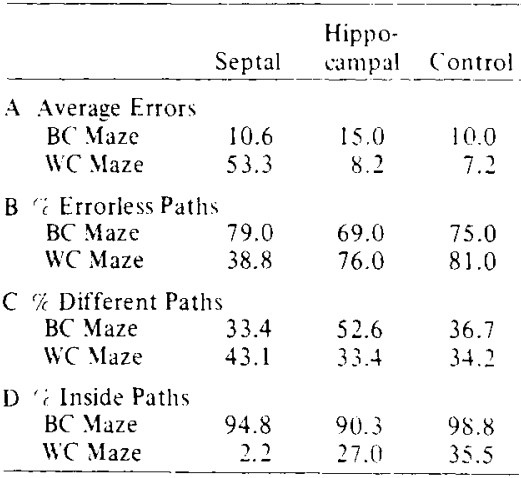


hypothesis that the septal area modulates the effects of light stimulation, and that in the absence of such modulation, because of the lesion, light stimulation becomes highly aversive for septal animals. This remains for further investigation.

\section{REFERFNCES}

DASHIF:LL, J. F. Direction orientation in maze running by the white rat. Comparative Psychology Monograph, 1930, 7, 1-72.

I:LLEN, P., \& BUTTER, J. External cue control of DRL performance in rats with septal lesions. Physiology \& Behavior, 1969, 4, 1-6.

ELLEN, P., \& BATE, G. Qualitative differences in the maze performance of rats with septal lesions. Psychonomic Science, 1969, 1, 5-6.

LORENS, S., \& BROWN, T. Influence of stimulation of the septal area on visual evoked potentials. Experimental Neurology, 1967, 17 . 86-90.
PFl.fGGINO, L. J.. \& CUSHMAN, A. J. A stereotaxic atlas of the rat brain. New York: Meredith, 1967.

SCHWARTZBAUM, J. S., GREEN, R. H., BEATTY, W. W., \& THOMPSON, J. B. Acquisition of avoidance behavior following scptal lesions in the rat. Journal of Comparative \& Physiological Psychology, $1967.63,95-104$.

WINER, B. J. Statistical principles in experimental design. New York: McGraw-Hill, 1962.

\section{NOTES}

1. This research was supported in part by NSF Grant GB-7184.

2. We would like to acknowledge the assistance of Mrs. Katherine Harlan, Mrs. Maria Kelnhofer, and Mr. S. T. Smith.

3. A version of this paper was read at the Tenth Annual Meeting of the Psychonomic Society, November 1969 .

\section{Physostigmine: Effects on retention at different times after brief training}

\author{
LARRY R. SQUIRE, Albert Einstein \\ College of Medicine, Bronx, N.Y. 10461
}

Mice were given physostigmine $30 \mathrm{~min}$, 1 day, 3 days, 7 days, or 14 days after brief training in a position habit, which normal animals forget within 14 days. The curve generated by the retention scores at these times was a miniaturization of the curve generated by previous studies using anticholinesterases and prolonged training in a visual task.

Cholinesterase inhibition is known to affect performance depending on when after training it is initiated (Deutsch, 1969; Squire, 1969). Three different effects on the retention of a well-learned visual discrimination have consistently been obtained following the administration of anticholinesterases at different times after training (Deutsch, Hamburg, \& Dahl, 1966; Deutsch \& Leibowitz, 1966). Early in the iffetime of the habit (1-3 days), retention is normal. Subsequently (7-14 days), anticholinesterase impairs retention. Finally, late in the lifetime of the habit, when forgetting can be observed (28 days), retention is improved. If these effects reflect, as has been postulated, specific, sequential changes in memory fixation, then habits of shorter lifetimes might reveal the same sequence of effects, though not necessarily at the same time after training.

\section{SUBJECTS AND APPARATUS}

The Ss were 271 male albino mice obtained from Charles River Breeding and weighing $35-40 \mathrm{~g}$ at the time of training. They were housed 10 to the cage and provided with ad lib access to food and water. The apparatus was a $\mathrm{T}$-maze with stem $12 \mathrm{in.} \mathrm{long} \mathrm{and} \mathrm{each} \mathrm{arm} 7 \mathrm{in.} \mathrm{long.}$ The walls were $11 \frac{1}{2}$ in. high. The floor was a grid of 5/32-in. stainless steel rods, spaced $1 / 2$ in. apart, that could be charged with scrambled 4 -mA current.

\section{PROCEDURE}

For training, a mouse was placed on the charged grid of the $T$-maze facing the choice point. If it ran to the correct side, the shock was terminated and, 5 sec later, was removed from the maze and placed on a table. If the mouse ran to the incorrect side, the shock remained on until it entered the correct arm. Training continued with an intertrial interval of $15-25 \mathrm{sec}$ until a mouse made three correct choices in four consecutive trials. Half of the mice were trained to choose the left arm of the maze and half were trained to choose the right arm. The procedure during retention tests was identical to that during original training. Retention testing continued until a mouse attained a criterion of three correct choices in four consecutive trials.

Mice were assigned to one of five groups, which were tested for retention $45 \mathrm{~min}$ 1 day, 3 days, 7 days, or 14 days after completion of original training. Half the mice of each group were given physostigmine salicylate $(.4 \mathrm{mg} / \mathrm{kg})$ I.P. $15 \mathrm{~min}$ before the retention test. The other half were given an equivalent volume of distilled water vehicle. Those mice failing during original learning to reach criterion within 12 trials $(\mathrm{N}=6)$ were elimianted. Thirteen mice given physostigmine did not consistently run in response to shock during the retention test and were discarded. Those mice requiring more than 12 trials to reach criterion during retention $(\mathrm{N}=7)$ were assigned a retention score of 12.

The difference scores (trials to learn trials to relearn) for each group closely approximated a normal distribution. Accordingly, two-tailed $t$ tests were used to compare the difference scores of independent groups. Savings within groups were evaluated with Wilcoxon matched-pairs, signed-ranks tests.

\section{RESULTS}

The mean number of trials required to reach criterion during original learning was 5.1 (range of means for 10 subgroups, 4.9-5.6). Trials to criterion during retention tests for both experimental and control groups are presented in Fig. 1. Control animals exhibited savings when tested $45 \mathrm{~min}, 1$ day, 3 days, or 7 days after learning $(\mathrm{p}<.05)$, but forgot the task within 14 days. After 14 days, control animals required as many trials (5.5) to relearn the task as had been required to learn it originally. Mice given physostigmine and tested $45 \mathrm{~min}, 1$ day, or 3 days after training exhibited significant savings at each interval $(p<.05)$, and were not significantly different from control Ss given their retention tests at the corresponding times. However, mice given psychostigmine 7 days after training did not exhibit savings. They learned originally in 5.2 trials and, 7 days after training, required 4.7 trials to relearn $(p>.1)$. The difference between the scores of experimental and control mice did not reach significance $(t=1.1, p>.2)$. Finally,

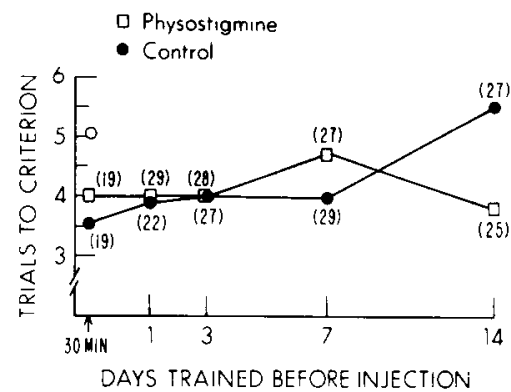

Fig. 1. Trials required to relearn the task at different times after training. The numbers in parentheses indicate the number of mice in each group. $O$ indicates the mean number of trials required by all mice to learn the task originally. 